\title{
Retraction
}

\section{Retracted: Some Results for Periodic Solutions of a Kind of Liénard Equation}

\section{Journal of Function Spaces}

Received 28 November 2020; Accepted 28 November 2020; Published 21 December 2020

Copyright $\odot 2020$ Journal of Function Spaces. This is an open access article distributed under the Creative Commons Attribution License, which permits unrestricted use, distribution, and reproduction in any medium, provided the original work is properly cited.

Journal of Function Spaces has retracted the article titled "Some Results for Periodic Solutions of a Kind of Liénard Equation" [1], due to significant overlap with a previous publication [2] without citation.

The authors and the editorial board approved this retraction.

\section{References}

[1] Y. Wang and X. Yi, "Some Results for Periodic Solutions of a Kind of Liénard Equation," Journal of Function Spaces, vol. 2015, Article ID 519747, 5 pages, 2015.

[2] Y. Wang and L. Zhang, "Novel results on periodic solutions of Liénard type p-Laplacian equation," Applied Mathematics ENotes, vol. 12, pp. 62-69, 2012, http://www.math.nthu.edu.tw/ $\sim$ amen/2012/110903-2.pdf. 


\title{
Some Results for Periodic Solutions of a Kind of Liénard Equation
}

\author{
Yong Wang ${ }^{1,2,3}$ and Xiangyi Yi ${ }^{1}$ \\ ${ }^{1}$ State Key Laboratory of Oil and Gas Reservoir Geology and Exploitation, Chengdu University of Technology, Chengdu, \\ Sichuan 610059, China \\ ${ }^{2}$ School of Sciences, Southwest Petroleum University, Chengdu, Sichuan 610500, China \\ ${ }^{3}$ State Key Laboratory of Oil and Gas Reservoir Geology and Exploitation, Southwest Petroleum University, Chengdu, \\ Sichuan 610500, China \\ Correspondence should be addressed to Yong Wang; ywangsc@gmail.com
}

Received 30 June 2014; Accepted 1 July 2014

Academic Editor: Kishin Sadarangani

Copyright (C 2015 Y. Wang and X. Yi. This is an open access article distributed under the Creative Commons Attribution License, which permits unrestricted use, distribution, and reproduction in any medium, provided the original work is properly cited.

We investigate the following Liénard-type $p$-Laplacian equation with a deviating argument $\left(\varphi_{p}\left(x^{\prime}(t)\right)\right)^{\prime}+f(x(t)) x^{\prime}(t)+\beta(t) g(x(t-$ $\tau(t)))=e(t)$. Some new criteria for guaranteeing the existence and uniqueness of periodic solutions of this equation are given by using the Manásevich-Mawhin continuation theorem and some analysis techniques. Our results hold under weaker conditions than some known results from the literature and are more effective. In the last section, an illustrative example is provided to demonstrate the applications of the theoretical results.

\section{Introduction}

In this present paper, we consider the following Liénard-type p-Laplacian equation with a deviating argument:

$$
\left(\varphi_{p}\left(x^{\prime}(t)\right)\right)^{\prime}+f(x(t)) x^{\prime}(t)+\beta(t) g(x(t-\tau(t)))=e(t),
$$

where $p>1, \varphi_{p}: \mathbb{R} \rightarrow \mathbb{R}$, and $\varphi_{p}(s)=|s|^{p-2} s$ is a one-dimensional $p$-Laplacian; $f, e \in C(\mathbb{R}, \mathbb{R}), \beta, \tau, g \in$ $C^{1}(\mathbb{R}, \mathbb{R})$, and $\beta(t)$ and $\tau(t)$ are two $T$-periodic functions with $\int_{0}^{T} e(t) d t=0, T>0$.

As is known, the Liénard equation can be derived from many fields, such as physics, mechanics, and engineering technique fields, and an important question is whether this equation can support periodic solutions. In the past few years, a lot of researchers have contributed to the theory of this equation with respect to the existence of periodic solutions. For example, in 1928, Liénard [1] discussed the existence of periodic solutions of the following equation:

$$
x^{\prime \prime}(t)+f(x(t)) x^{\prime}(t)+k(x(t)) x(t)=0,
$$

where $f, k \in C(\mathbb{R}, \mathbb{R})$; some sufficient conditions for securing the existence of periodic solutions were established. Afterwards, Levinson and Smith [2] also studied (2) and obtained some new results on the existence of periodic solutions. In 1977, some continuation theorems in [3] were introduced by Gaines and Mawhin. Applying these continuation theorems, many authors discussed the existence of periodic solutions of $(2)$ and generalized the results obtained in $[1,2]$ (see, e.g., [4-7]); a few authors studied the existence and uniqueness of periodic solutions of (2) (see [8, 9]). In 1998, Manásevich and Mawhin [10] studied periodic solutions for certain nonlinear systems with $p$-Laplacian-like operators and provided some new continuation theorems which extended some results in [3]. Subsequently, some authors discussed the existence of periodic solutions of certain Liénard-type $p$-Laplacian equations (see, e.g., [11-15]) using these generalized continuation theorems. However, as far as we know, there exist much fewer results on the existence and uniqueness of periodic solutions of (1). The main difficulty lies in the first term $\left(\varphi_{p}\left(x^{\prime}(t)\right)\right)^{\prime}$ of $(1)$ (i.e., the $p$-Laplacian operator $\varphi_{p}: \mathbb{R} \rightarrow \mathbb{R}$; $\varphi_{p}(s)=|s|^{p-2} s$ is nonlinear when $p \neq 2$ ), the existence of which prevents the usual methods of finding some criteria for 
guaranteeing the uniqueness of periodic solutions of (2) from working. Recently, Gao and Lu [16] discussed the existence and uniqueness of periodic solution of (1) by translating (1) into a two-dimensional system and got some results as follows.

Theorem 1 (see [16]). Assume that the following condition holds:

$$
\begin{gathered}
\left(\mathrm{H}_{0}\right) \beta(t)>0, g^{\prime}(x)<0 \text {, and } \tau(t) \equiv \varepsilon \text { ( } \varepsilon \text { being sufficiently } \\
\text { small constant) for all } t, x \in \mathbb{R} .
\end{gathered}
$$

Then (1) has at most one T-periodic solution.

Remark 2. However, upon examining their proof of Theorem 1, it was found that if $\tau(t) \neq 0 \forall t \in \mathbb{R}$, then Theorem 1 does not hold; more precisely, for arbitrarily given $\varepsilon>0, v\left(t^{*}\right)=y_{1}\left(t^{*}\right)-y_{2}\left(t^{*}\right)>0$ does not positively imply $v\left(t^{*}-\varepsilon\right)=y_{1}\left(t^{*}-\varepsilon\right)-y_{2}\left(t^{*}-\varepsilon\right)>0$; thus, in line 3 on page 377 in [16], the inequality $v^{\prime \prime}\left(t^{*}\right)>0$ is incorrect. On the other hand, if $\tau(t) \equiv 0$, then Theorem 1 is correct.

Theorem 3 (see [16]). Assume that the following conditions hold.

$\left(\mathrm{H}_{1}\right)$ There exist $r_{1}>0, r_{2}>0, m>0$, and $d \geq 0$ such that

(i) $r_{1}|u|^{m} \leq|g(u)| \leq r_{2}|u|^{m}$ for all $|u|>d$,

(ii) $u g(u)<0$ for all $|u|>d$.

$\left(\mathrm{H}_{2}\right)$ Consider

$A:= \begin{cases}{\left[\frac{r_{2} T}{r_{1} \int_{0}^{T}(\beta(t)+1) d t}\right]^{1 / m} 2^{(1-m) / m}<1,} & 0<m \leq 1, \\ {\left[\frac{r_{2} T}{r_{1} \int_{0}^{T}(\beta(t)+1) d t}\right]^{1 / m}<1,} & m>1 .\end{cases}$

$\left(\mathrm{H}_{3}\right)$ Suppose one of the following conditions holds:

(i) $m=p-1$ and $\beta_{\infty} r_{2} T^{m+2-((m+1) / p)} / 2(1-A)^{m+1}<$ 1 ,

(ii) $m<p-1$,

where $\beta_{\infty}=\max _{t \in[0, T]}|\beta(t)|$.

Then (1) has at least one T-periodic solution.

Remark 4. However, upon examining their proof of Theorem 3.2 in [16], we have found that the conditions $\left(\mathrm{H}_{1}\right)(\mathrm{i}),\left(\mathrm{H}_{2}\right)$, and $\left(\mathrm{H}_{3}\right)$ can be dropped.

In this paper, we are keen to dispel any perception that the mathematical proofs of existence and uniqueness that we present are merely verifying facts which might already be obvious in other disciplines, based on purely physical considerations. In particular, in many nonlinear problems arising in practical dynamical systems, physical reasoning alone is not sufficient or fully convincing. In these cases, questions of existence and uniqueness are of importance in understanding the full range of solution behaviour possible and represent a genuine mathematical challenge. The answers to these mathematical questions then provide the basis for obtaining the best numerical solutions to these problems and for determining other important practical aspects of the solution behaviour.

We now reconsider the periodic solutions of (1). The main purpose of this paper is to establish some new criteria for guaranteeing the existence and uniqueness of periodic solution of (1). We obtain some new sufficient conditions for securing the existence and uniqueness of periodic solutions of (1) by using the Manásevich-Mawhin continuation theorem and some analysis techniques. Our results extend and improve the above-mentioned Theorems 3.1 and 3.2 in [16] (see Remarks 9 and 14 and Example 13).

\section{Lemmas}

For convenience, define

$$
|x|_{\infty}=\max _{t \in[0, T]}|x(t)|, \quad\left|x^{\prime}\right|_{\infty}=\max _{t \in[0, T]}\left|x^{\prime}(t)\right|,
$$

$|x|_{k}=\left(\int_{0}^{T}|x(t)|^{k} d t\right)^{1 / k}$.

Let

$$
C_{T}^{1}:=\left\{x \in C^{1}(\mathbb{R}, \mathbb{R}): x \text { is } T \text {-periodic }\right\},
$$

which is a Banach space with the norm

$$
\|x\|=\max \left\{|x|_{\infty},\left|x^{\prime}\right|_{\infty}\right\} \text {. }
$$

The following conditions will be used later:

$\left(\mathrm{A}_{0}\right) \beta(t)>0, g^{\prime}(x)<0$, and $\tau(t) \equiv 0$, for all $t, x \in \mathbb{R}$,

$\left(\mathrm{A}_{0}^{\prime}\right) \beta(t)<0, g^{\prime}(x)>0$, and $\tau(t) \equiv 0$, for all $t, x \in \mathbb{R}$,

$\left(\mathrm{A}_{1}\right)$ there exists $d \geq 0$, such that $u g(u)<0$ for all $|u| \geq d$,

$\left(\mathrm{A}_{1}^{\prime}\right)$ there exists $d \geq 0$, such that $u g(u)>0$ for all $|u| \geq d$.

For the periodic boundary value problem

$$
\begin{gathered}
\left(\varphi_{p}\left(x^{\prime}(t)\right)\right)^{\prime}=h\left(t, x, x^{\prime}\right), \quad x(0)=x(T), \\
x^{\prime}(0)=x^{\prime}(T),
\end{gathered}
$$

where $h \in C\left(\mathbb{R}^{3}, \mathbb{R}\right)$ is $T$-periodic in the first variable, the following continuation theorem can be induced directly from the theory in [10] and is cited as Lemma 1 in [17].

Lemma 5 (Manásevich and Mawhin [10]). Let $B=\left\{x \in C_{T}^{1}\right.$ : $\|x\|<r\}$ for some $r>0$. Suppose the following two conditions hold.

(i) For each $\lambda \in(0,1)$ the problem $\left(\varphi_{p}\left(x^{\prime}(t)\right)\right)^{\prime}=$ $\lambda h\left(t, x, x^{\prime}\right)$ has no solution on $\partial B$. 
(ii) The continuous function $F$ defined on $\mathbb{R}$ by $F(a)=$ $(1 / T) \int_{0}^{T} h(t, a, 0) d t$ is such that $F(-r) F(r)<0$.

Then the periodic boundary value problem (7) has at least one $T$-periodic solution on $\bar{B}$.

According to Theorem 3.1 in [16] and the abovementioned Remark 2, we have the following results.

Lemma 6. Suppose $\left(A_{0}\right)$ holds. Then (1) has at most one Tperiodic solution.

Lemma 7. Suppose $\left(A_{0}^{\prime}\right)$ holds. Then (1) has at most one Tperiodic solution.

\section{Main Results}

Now we are in the position to present our main results.

Theorem 8. Suppose $\left(A_{1}\right)$ holds. Then (1) has at least one $T$ periodic solution.

Proof. Consider the homotopic equation of (1):

$$
\begin{gathered}
\left(\varphi_{p}\left(x^{\prime}(t)\right)\right)^{\prime}+\lambda f(x(t)) x^{\prime}(t)+\lambda \beta(t) g(x(t-\tau(t))) \\
=\lambda e(t), \quad \lambda \in(0,1) .
\end{gathered}
$$

First, we prove that the set of $T$-periodic solutions of (8) are bounded in $C_{T}^{1}$. Let $S \subset C_{T}^{1}$ be the set of $T$-periodic solutions of (8). If $S=\emptyset$, the proof is ended. Suppose $S \neq \emptyset$, and let $x \in S$. Noticing that $x(0)=x(T), x^{\prime}(0)=x^{\prime}(T), \varphi_{p}(0)=0$, and $\int_{0}^{T} e(t) d t=0$, it follows from (8) that

$$
\int_{0}^{T} \beta(t) g(x(t-\tau(t))) d t=0
$$

which, together with $\beta(t)>0$, implies that there exists $t_{0} \in$ $[0, T]$ such that

$$
g\left(x\left(t_{0}-\tau\left(t_{0}\right)\right)\right)=0 .
$$

Denoting $\bar{t}_{0}=t_{0}-\tau\left(t_{0}\right)$, by $\left(\mathrm{A}_{1}\right),(10)$ implies

$$
\left|x\left(\bar{t}_{0}\right)\right|<d .
$$

Then, for any $t \in\left[\bar{t}_{0}, \bar{t}_{0}+T\right]$,

$$
\begin{aligned}
|x(t)| & =\left|x\left(\bar{t}_{0}\right)+\int_{\bar{t}_{0}}^{t} x^{\prime}(s) d s\right|<d+\int_{\bar{t}_{0}}^{\bar{t}_{0}+T}\left|x^{\prime}(s)\right| d s \\
& =d+\int_{0}^{T}\left|x^{\prime}(s)\right| d s,
\end{aligned}
$$

which leads to

$$
|x|_{\infty}=\max _{t \in\left[\bar{t}_{0}, \bar{t}_{0}+T\right]}|x(t)|<d+\left|x^{\prime}\right|_{1} .
$$

Define $E_{1}=\{t: t \in[0, T],|x(t-\tau(t))|>d\}$ and $E_{2}=\{t:$ $t \in[0, T],|x(t-\tau(t))| \leq d\}$. Multiplying $x(t)$ and (8) and then integrating from 0 to $T$, by $\left(A_{1}\right)$, we have

$$
\begin{aligned}
\int_{0}^{T}\left|x^{\prime}(t)\right|^{p} d t= & -\int_{0}^{T}\left(\varphi_{p}\left(x^{\prime}(t)\right)\right)^{\prime} x(t) d t \\
= & \lambda \int_{0}^{T} \beta(t) g(x(t-\tau(t)) x(t)) d t \\
& -\lambda \int_{0}^{T} e(t) x(t) d t \\
= & \lambda \int_{E_{1}} \beta(t) g(x(t-\tau(t)) x(t)) d t \\
& +\lambda \int_{E_{2}} \beta(t) g(x(t-\tau(t)) x(t)) d t \\
& -\lambda \int_{0}^{T} e(t) x(t) d t \\
\leq & \lambda \int_{E_{2}} \beta(t) g(x(t-\tau(t)) x(t)) d t \\
& -\lambda \int_{0}^{T} e(t) x(t) d t \\
\leq & \int_{E_{2}}|\beta(t) g(x(t-\tau(t)))||x(t)| d t \\
& +\int_{0}^{T}|e(t)||x(t)| d t \\
\leq & \left(\max _{t \in[0, T], x \mid \leq d}|\beta(t) g(x)|+|e|_{\infty}\right) T|x|_{\infty} .
\end{aligned}
$$

Let $M_{0}=\left(\max _{t \in[0, T],|x| \leq d}|\beta(t) g(x)|+|e|_{\infty}\right) T$. Then we obtain

$$
\left|x^{\prime}\right|_{p} \leq M_{0}^{1 / p}|x|_{\infty}^{1 / p}
$$

Let $q>1$ such that $1 / p+1 / q=1$. Then by Hölder inequality we have

$$
\left|x^{\prime}\right|_{1} \leq\left|x^{\prime}\right|_{p}|1|_{q}=T^{1 / q}\left|x^{\prime}\right|_{p} .
$$

By (13), (15), and (16), we can get

$$
\left|x^{\prime}\right|_{1} \leq T^{1 / q} M_{0}^{1 / p}\left(d+\left|x^{\prime}\right|_{1}\right)^{1 / p}
$$

which yields that there exists $M_{1}>0$ such that $\left|x^{\prime}\right|_{1}<M_{1}$ since $p>1$, and this, together with (13), implies that $|x|_{\infty}<$ $d+M_{1}$. 
Meanwhile, there exists $\widehat{t}_{0} \in[0, T]$ such that $x^{\prime}\left(\widehat{t}_{0}\right)=0$ since $x(0)=x(T)$. Then by (8) we have, for $t \in\left[\hat{t}_{0}, \widehat{t}_{0}+T\right]$,

$$
\begin{aligned}
& \left|\varphi_{p}\left(x^{\prime}(t)\right)\right| \\
& =\left|\int_{\hat{t}_{0}}^{t}\left(\varphi_{p}\left(x^{\prime}(s)\right)\right)^{\prime} d s\right| \\
& =\lambda\left|\int_{\hat{t}_{0}}^{t}\left(f(x(s)) x^{\prime}(s)+\beta(s) g(x(s-\tau(s)))+e(s)\right) d s\right| \\
& \quad \leq \int_{0}^{T}\left(|f(x(s))|\left|x^{\prime}(s)\right|+|\beta(s) g(x(s-\tau(s)))|\right. \\
& \quad+|e(s)|) d s \\
& <F M_{1}+\left(G+|e|_{\infty}\right) T,
\end{aligned}
$$

where $F=\max \left\{|f(x)|:|x| \leq d+M_{1}\right\}$ and $G=$ $\max \left\{|\beta(t) g(x)|: t \in[0, T],|x| \leq d+M_{1}\right\}$. So we obtain

$$
\begin{aligned}
\left|x^{\prime}\right|_{\infty} & =\max _{t \in[0, T]}\left\{\left|\varphi_{p}\left(x^{\prime}(t)\right)\right|^{1 /(p-1)}\right\} \\
& <\left(F M_{1}+\left(G+|e|_{\infty}\right) T\right)^{1 /(p-1)} .
\end{aligned}
$$

Let $M=\max \left\{d+M_{1},\left(F M_{1}+\left(G+|e|_{\infty}\right) T\right)^{1 /(p-1)}\right\}$. Then $\|x\|<$ $M$.

Second, we prove the existence of $T$-periodic solutions of (1). Set

$$
\begin{aligned}
& h\left(t, x(t), x^{\prime}(t)\right) \\
& \quad=-f(x(t)) x^{\prime}(t)-\beta(t) g(x(t-\tau(t)))+e(t) ;
\end{aligned}
$$

then (8) is equivalent to the following equation:

$$
\left(\varphi_{p}\left(x^{\prime}(t)\right)\right)^{\prime}=\lambda h\left(t, x(t), x^{\prime}(t)\right), \quad \lambda \in(0,1) .
$$

Set

$$
B=\left\{x: x \in C_{T}^{1},\|x\|<r\right\}, \quad \text { where } r \geq M ;
$$

by (20), we know that (21) has no solution on $\partial B$ as $\lambda \in(0,1)$, so condition (i) of Lemma 5 is satisfied. By the definition of $F$ in Lemma 5 we get

$$
\begin{aligned}
F(a) & =\frac{1}{T} \int_{0}^{T} h(t, a, 0) d t=\frac{1}{T} \int_{0}^{T}(e(t)-\beta(t) g(a)) d t \\
& =-\frac{1}{T} \int_{0}^{T} \beta(t) g(a) d t .
\end{aligned}
$$

This, together with $\beta(t)>0$ for all $t \in \mathbb{R}$ and $\left(\mathrm{A}_{1}\right)$, yields that $F(r) F(-r)<0$; that is, condition (ii) of Lemma 5 is satisfied. Therefore, it follows from Lemma 5 that there exists a $T$ periodic solution $x(t)$ of (1). This completes the proof.

Remark 9. It is easy to see that Theorem 8 in this study holds under weaker conditions than Theorem 3.2 in [16].
According to the above discussion, we can also get the following result.

Theorem 10. Suppose $\left(A_{1}^{\prime}\right)$ holds. Then (1) has at least one Tperiodic solution.

Together with Lemmas 6 and 7 and Theorems 8 and 10, we can directly lead to two theorems as follows.

Theorem 11. Suppose $\left(A_{0}\right)$ and $\left(A_{1}\right)$ hold. Then (1) has a unique T-periodic solution.

Theorem 12. Suppose $\left(A_{0}^{\prime}\right)$ and $\left(A_{1}^{\prime}\right)$ hold. Then (1) has a unique T-periodic solution.

\section{Example and Remark}

In this section, we apply the main results obtained in the previous sections to an example.

Example 13. Consider the existence and uniqueness of a $2 \pi$ periodic solution of the following Liénard-type $p$-Laplacian equation:

$$
\left(\varphi_{p}\left(x^{\prime}(t)\right)\right)^{\prime}+f(x(t)) x^{\prime}(t)+\beta(t) g(x(t))=e(t),
$$

where $p>1, f \in C(\mathbb{R}, \mathbb{R}), \beta(t)=1+\cos ^{2} t, g(x)=-x^{3}-2 x$, $e(t)=\cos t$, and $T=2 \pi$.

Proof. If $p<4$, condition $\left(\mathrm{H}_{3}\right)$ in Theorem 3.3 in [16] does not hold any more since $m=3>p-1$. Therefore, Theorem 3.3 in [16] fails, while our criterion in Theorem 11 in this study remains applicable, as we now show. Let $d$ be an arbitrary positive constant; then we can easily check that conditions $\left(\mathrm{A}_{0}\right)$ and $\left(\mathrm{A}_{1}\right)$ in Theorem 11 in this study hold. Hence, Theorem 11 shows that there exists a unique $2 \pi$ periodic solution of (24).

Remark 14. This example demonstrates that the conditions in our Theorem 11 are weaker than those conditions in Theorem 3.3 in [16] when $\tau(t) \equiv 0$ and are able to demonstrate the existence of a unique periodic solution to certain Liénardtype $p$-Laplacian equations, which the latter cannot decide about. Therefore, our results extend and improve the results in $[16]$.

\section{Conflict of Interests}

The authors declare that there is no conflict of interests regarding the publication of this paper.

\section{Acknowledgments}

This work was supported by the National Program on Key Basic Research Project (973 Program, Grant no. 2011CB201005), the Sichuan Youth Science and Technology Fund (no. 2011JQ0044), and the scientific research starting project of SWPU (no. 2014QHZ031). 


\section{References}

[1] A. Liénard, "Étude des oscillations entretenues," Revue Générale de l'Électricité, vol. 28, pp. 901-946, 1928.

[2] N. Levinson and O. K. Smith, "A general equation for relaxation oscillations," Duke Mathematical Journal, vol. 9, pp. 382-403, 1942.

[3] R. E. Gaines and J. L. Mawhin, Coincidence Degree, and Nonlinear Differential Equations, vol. 568 of Lecture Notes in Mathematics, Springer, Berlin, Germany, 1977.

[4] N. P. Các, "Periodic solutions of a Liénard equation with forcing term," Nonlinear Analysis: Theory, Methods \& Applications, vol. 43, pp. 403-415, 2001.

[5] S. Lu and W. Ge, "Periodic solutions for a kind of second order differential equation with multiple deviating arguments," Applied Mathematics and Computation, vol. 146, no. 1, pp. 195209, 2003.

[6] S. Lu and W. Ge, "Periodic solutions for a kind of Liénard equation with a deviating argument," Journal of Mathematical Analysis and Applications, vol. 289, no. 1, pp. 231-243, 2004.

[7] Z. Wang, "Periodic solutions of the second-order forced Liénard equation via time maps," Nonlinear Analysis: Theory, Methods \& Applications, vol. 48, pp. 445-460, 2002.

[8] B. Liu, "Existence and uniqueness of periodic solutions for a kind of Rayleigh equation with two deviating arguments," Computers \& Mathematics with Applications, vol. 55, no. 9, pp. 2108-2117, 2008.

[9] Q. Zhou and F. Long, "Existence and uniqueness of periodic solutions for a kind of Liénard equation with two deviating arguments," Journal of Computational and Applied Mathematics, vol. 206, no. 2, pp. 1127-1136, 2007.

[10] R. Manásevich and J. Mawhin, "Periodic solutions for nonlinear systems with $p$-Laplacian-like operators," Journal of Differential Equations, vol. 145, no. 2, pp. 367-393, 1998.

[11] W. Cheung and J. Ren, "Periodic solutions for $p$-Laplacian Liénard equation with a deviating argument," Nonlinear Analysis, vol. 59, no. 1-2, pp. 107-120, 2004.

[12] W.-S. Cheung and J. Ren, "On the existence of periodic solutions for $p$-Laplacian generalized Liénard equation," Nonlinear Analysis: Theory, Methods \& Applications, vol. 60, no. 1, pp. 65-75, 2005.

[13] B. Liu, "Periodic solutions for Liénard type $p$-LAPlacian equation with a deviating argument," Journal of Computational and Applied Mathematics, vol. 214, no. 1, pp. 13-18, 2008.

[14] B. Liu, "Existence and uniqueness of periodic solutions for a kind of Liénard type $p$-Laplacian equation," Nonlinear Analysis: Theory, Methods \& Applications, vol. 69, no. 2, pp. 724-729, 2008.

[15] S. Lu, "Existence of periodic solutions to a $p$-Laplacian Liénard differential equation with a deviating argument," Nonlinear Analysis: Theory, Methods \& Applications, vol. 68, no. 6, pp. 1453-1461, 2008.

[16] F. Gao and S. Lu, "New results on the existence and uniqueness of periodic solutions for Liénard type p-LAPlacian equation," Journal of the Franklin Institute, vol. 345, no. 4, pp. 374-381, 2008.

[17] F. Zhang and Y. Li, "Existence and uniqueness of periodic solutions for a kind of Duffing type p-Laplacian equation," Nonlinear Analysis: Real World Applications, vol. 9, no. 3, pp. 985-989, 2008.

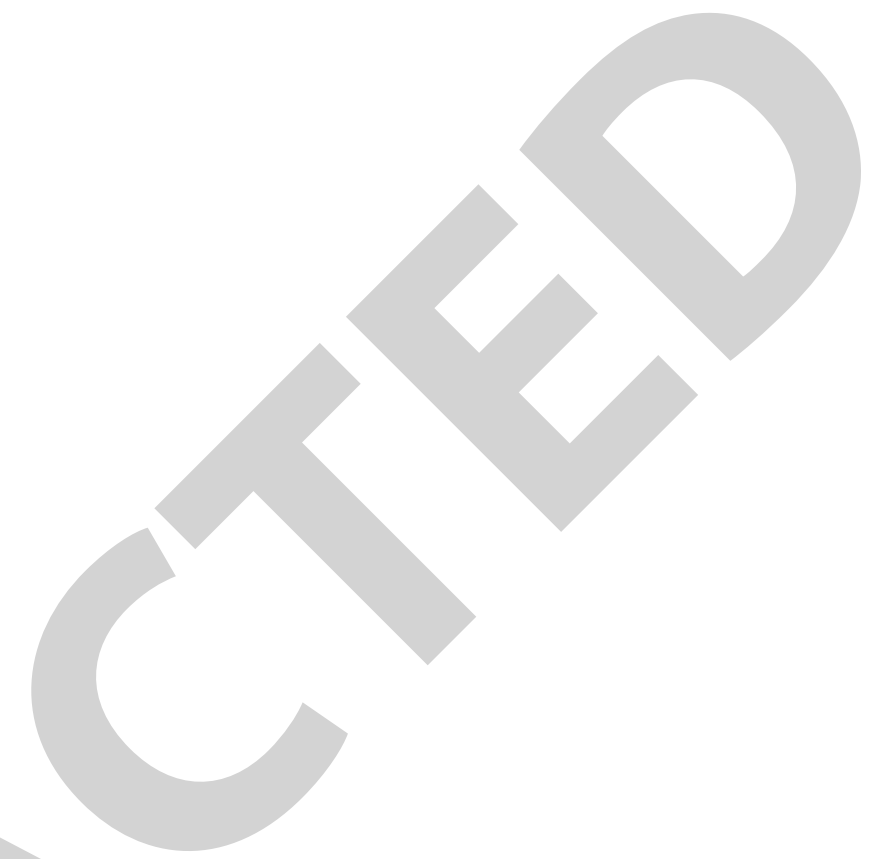

